Fecha de recepción: febrero 2010 Fecha de aceptación: marzo 2010 Versión final: agosto 2010

\section{Las nuevas relaciones con los medios. En un mundo de comunicaciones directas, ¿es necesario hacer media relations?}

Alberto Arébalos ${ }^{(*)}$

\begin{abstract}
Resumen: Este artículo corresponde al capítulo XI del libro La revolución horizontal - El poder de la comunicación en manos de la gente, presentado a fines de 2009 en la Facultad de Diseño y Comunicación de la Universidad de Palermo. Sus autores -Alberto Arébalos y Gonzalo Alonso-, reflexionan sobre las claves para entender el cambio en la forma en que las marcas, empresas y políticos se relacionan y comunican con los consumidores, clientes y votantes. Puntualmente este capítulo, aborda el desafío de la gestión de las relaciones públicas y las relaciones con los medios, empleando una serie de herramientas que potencian y renuevan herramientas tradicionales, a partir de una nueva cultura relacional emergente. Reflexiona sobre la optimización de los comunicados de prensa, sobre mecanismos como RSS que multiplican el alcance de las noticias corporativas; y sobre los costosos video news releases que ahora con un menor costo, pueden alcanzar audiencias mayores.
\end{abstract}

Palabras claves: Audiencias - Comunicación Corporativa - comunicación digital - Comunicación Institucional - comunicación organizacional - Comunicadores - Dircom - Director de Comunicación - marcas - público externo - público interno - relaciones - Relaciones con la Prensa - Relaciones con los Medios - Relaciones Institucionales - Relaciones Públicas - redes sociales - reputación corporativa - social media - tendencias.

[Resúmenes en inglés y portugués y currículum en la página 100]

"Los comunicados de prensa son escritos por comités, editados por abogados y enviados después con un gran gasto de dinero a los cestos de basura, digitales y reales, de decenas de miles de periodistas." (Silicon Valley Watcher, sf)

"Escribir es fácil, todo lo que hay que hacer es tachar las palabras equivocadas" (Mark Twain, sf)

Quienes hemos sido periodistas sabemos que una de las pocas cosas que nos disgustan acerca de la profesión es lidiar con relacionistas públicos que no tienen la más mínima idea de qué nos interesa, cómo y qué cubrimos, qué ángulos son los noticiosos y, en general, desconocen los principios básicos de lo que significa ser periodista. Numerosos periodistas han practicado el arte de la puntería, tratando de encestar las pelotitas hechas con papel de faxes con inútiles comunicados de prensa o ideas de notas sobre calzado deportivo que llegan a las manos del jefe de la sección de policiales. 
Se han gastado ríos de tinta para comentar este divorcio que, pese a todo, sigue existiendo. Basta hablar o hacer algún estudio de la percepción que los periodistas tienen acerca de la comunicación corporativa y uno de los principales objetos de críticas son las agencias de relaciones públicas, que desconocen cómo trabajan en las redacciones; y los odiados comunicados de prensa. Lo que hace aún más inexplicable la situación es que entender cómo trabajan las redacciones y los periodistas es relativamente fácil. Sólo basta con preguntar y enviar a los miembros más inexpertos a visitar una redacción -offline, online, de radio o de TV- y tratar de entender qué mueve a un periodista, qué limitaciones de espacio tiene, cuántas ofertas de nota recibe por día $y$, en definitiva, qué es una noticia. Por otra parte, el comunicado de prensa bien escrito sigue siendo útil en muchos casos, y cuando parecía que marchaba a un entierro sin deudos, el auge de la Web 2.0 le ha dado una nueva vida.

En este capítulo veremos, entonces, cómo hacer relaciones públicas y relaciones con los medios empleando una serie de herramientas que potencian y renuevan herramientas tradicionales. Reflexionaremos -entre otras cosas- sobre la optimización de los comunicados de prensa que nos ayudan a ser encontrados por los buscadores, sobre mecanismos como RSS que multiplican el alcance de las noticias corporativas; y sobre los costosos Video News Releases (o comunicados de prensa visuales) que ahora se pueden hacer con un menor costo, subirse a YouTube y alcanzar audiencias aún mayores que con los canales de televisión tradicionales.

\section{Relaciones con los bloggers}

Antes de avanzar con un desarrollo exhaustivo que explique cómo deberían ser las nuevas relaciones con los medios, queremos incluir una conversación que tuvimos con Mariano Amartino y que nos ayuda a ilustrar los errores reincidentes en las relaciones públicas. Amartino es un reconocido blogger argentino. En Denker Über ${ }^{1}$ - escribe sobre tecnología, estrategias y hechos vinculados a Internet, y por la calidad de su contenido es considerado un referente en la blogósfera. De hecho, gracias a su trayectoria fue incorporado, en 2009, a Hipertextual -una de las redes de blogs más grandes a nivel hispano- como Director General. Esta entrevista pone de manifiesto que tanto periodistas como bloggers deben ser abordados con sentido común e inteligencia más que con las antiguas herramientas de la profesión.

Pregunta: ¿Cómo es tu relación con las empresas? ¿Cómo accede un profesional de relaciones públicas de las empresas a un blogger?

MA: Hay dos maneras. Una de ellas es la tradicional: me meten en una base de datos en la cual me mandan todos los días mails con comunicados de prensa que nunca leo y siempre marco como spam, rogando al cielo que Google o Gmail no me los muestre más porque me hacen perder el tiempo. Porque, en general, están escritos para periodistas que, no solamente no saben del tema, sino que están obligados a escribir.

La otra manera, es generando una relación con la gente que está en la empresa. O sea, se acercan las empresas, a través de su agencia de prensa al principio; y en general, cuando ven que del otro lado hay alguien que conoce algo del tema y con el cual compartís una pasión entablan una relación.

$\mathrm{P}:$ ¿Y cómo te contactan, por teléfono o te escriben un mail personal? 
MA: Escriben un mail. No, las agencias de prensa no personalizan nada. Las agencias de prensa, en general, tienen una base de datos de periodistas y mandan comunicados esperando que se publiquen.

P: Entonces, ¿cómo hacen para generar una relación?

MA: Es que no la generan. O sea, de la manera tradicional no la generan. La generan de esta segunda manera que es mandando un mail personalizado, conociéndonos en persona cuando hay algún evento. Se empieza a generar una relación cuando ves que del otro lado hay alguien que sabe. Entonces, lo que se ve es que del otro lado hay alguien que conoce del mercado y que tiene cierta honestidad intelectual y, en base a eso, se genera (la relación). Después sucede algo típico y que es muy gracioso. Hay agencias de prensa que, como ven que yo escribo de tecnología, me mandan comunicados de prensa de cosas que a mí no me interesan para nada. Hay veces que publico en mi Twitter (en general mi Twitter es mucho más descarnado que mi blog) tweets que dicen: "los idiotas de Nextel me invitan al lanzamiento de un producto que, cuando les pido información para publicarlo, tardan dos semanas en dármela”.

P: Ese es otro tema: el acceso a la información, ¿de qué manera te parece que debería estar disponible la información de las empresas, a través de Twitter o alguna plataforma en particular?

MA: Primero, creo que deberían ser un poco más abiertos en cuanto a su comunicación; no ocultar todo y esperar para dar una exclusiva o esperar un lanzamiento mundial. ¿Por qué? Porque las empresas están acostumbradas a que el periodista tradicional saca sus notas de las cableras y la realidad es que yo no tengo acceso a la cablera (agencia de noticias). Yo leo, de mi mercado leo mucho y tengo mucha gente que son fuentes. Cuando a mí me mandan un comunicado de prensa, llegan 15 días después y es una vergüenza. Entonces, ¿qué es lo que tendrían que hacer? Tendrían que entender que están en un mundo globalizado, en el cual la información corre de una punta a la otra a través de publicaciones en un blog cualquiera o en la cuenta de Twitter de cualquier persona. Automáticamente, si es un contenido valioso, se va a replicar dentro de su mercado.

Entonces, lo que tienen que entender es que el mundo ya está hablando de ellos, que ya existen enlaces de información mucho más frecuentes. Por lo tanto, hay dos opciones: tratar de frenarlo y vivir un poco más encerrado, como vive Apple, que vive totalmente encerrado; o ser totalmente abierto como la gente de Sun. Los blogs de Sun son totalmente abiertos. Jeremy Schwartz, que es el CEO de Sun, escribe a veces sobre la estrategia que (la empresa) va a tener de acá a 5 años y eso no se ve en ninguna otra empresa. Cuando salió, por ejemplo, el navegador Chrome de Google, la gente de prensa a mí no me invitó al evento. Sinceramente, no tengo ni idea por qué no me invitaron. Ir a un evento periodístico a llevarme una camiseta no me interesa mucho. A mí me gusta la información. Pero, al no invitarme, me permitió -como ya había conseguido la información 24 horas antes y no tenía ningún tipo de invitación- poder publicarla antes que todos los que fueron. Yo conseguí la primicia, la publiqué antes y les arruiné la novedad. Lo lamento, no es mi culpa; pero aprendieron. Lo que tiene de bueno es que algunas empresas aprenden. Por ejemplo, con Google Chrome OS se dieron cuenta que había una fuga de información y que iba a ser linkeada y, automáticamente, los tipos publicaron una nota en 
su blog oficial y empezaron a hablar. En comunicación corporativa lo que tenés que hacer es tratar de que el mensaje salga de la empresa para poder modelar qué es lo que llega a las masas.

P: Y una empresa que quiere llegar a tu blog, ¿cómo debería contactarte?

MA: Con, al menos, un mail personalizado y algo de información. En realidad, es más fácil, cuando una empresa se quiere acercar a un blogger, el único consejo es: antes de mandarle un mail, antes que nada, lean su blog. Tienen que entender de qué está hablando, porque te suelen mandar un mail diciendo "Hola 'coma' Mariano 'coma' esperamos que estés bien, bla bla bla, queremos informarte de esta cosa". Si hubiesen entrado en tu blog, se hubiesen dado cuenta que vos lo publicaste hace una semana. Entonces, evidentemente, acá hay algo que les está fallando. Me gustaría que algunos leyeran mi blog, que sepan quién soy antes de escribir. Porque la realidad es que el mercado cambió: antes eran cinco empresas a las que vos le tenías que suministrar información. Está bien, eran 50 periodistas, pero dentro de esas 5 empresas. En Argentina eran La Nación, Clarín, Editorial Perfil, Editorial Abril y algún otro medio más. Después, 3 canales de televisión, 10 radios y se acabó, listo. Ahora tenés 300,000 blogs y, además tenés otras plataformas como Twitter, etc.

P: ¿También tenés un formulario de contacto en el blog?

MA: Tengo un formulario de contacto que lo pueden usar. Pero lo que hacen es poner el nombre de ellos, su dirección de mail y hacen 'copy-paste' del press release que me mandan. Odio los press releases, son una basura. Yo estoy seguro que si en un blog corporativo ponen la misma información que en un press release, pero le dan un toque humano, al menos yo le prestaría más atención, al menos lo leería. Hay press releases que... a la basura, es realmente a la basura. Nos consta que las opiniones de Amartino son compartidas casi con unanimidad por periodistas y bloggers en toda la región. Nuestra intención al exponer esta entrevista es generar conciencia sobre lo perjudicial y molesto que son las actitudes propias de las relaciones públicas tradicionales. La web 2.0 nos lleva a adoptar una nueva cultura relacional y a modificar ciertos hábitos.

\section{Nuevas actitudes para una nueva relación}

El comportamiento que debemos tomar para llegar a los nuevos medios debe ser personalizado y atravesar distintas plataformas. Incluso existen algunos detalles a tener en cuenta en la planificación de la comunicación que sumará valor a la relación final que logremos establecer. He aquí algunas formas adecuadas:

- Poner a disposición los artículos de la empresa u organización en redes sociales y agregadores de noticias como Digg, Fresqui o Google News.

- Realizar enlaces a ellos

- Aprovechar las redes profesionales y sociales como Facebook, Sonico, LinkedIn, Plaxo Pulse.

- Twitter es un excelente medio para avisar a bloggers que hay nueva información disponible o -mejor aún- que se va a hacer un anuncio pronto.

- El comunicado de prensa tradicional no es negocio en las relaciones con los bloggers. 
- Videos, crear demos de video de corta duración, intros, eventos, saludos o parodias, que sean específicas del mercado que tratamos de alcanzar.

- Podcasts, invitarlos a participar de podcasts como expertos o analistas. O crear entrevistas pregrabadas o discusiones que le interesen a los bloggers.

- En muchos casos habrá que adaptar el mensaje a un blogger o grupo de bloggers en particular. - Emplear bookmarks sociales, a través de servicios como, ma.gnolia y del.ici.ous. También contar con páginas construidas especialmente para proveer información de respaldo y perspectiva para ayudar a los bloggers a ganar experiencia y contexto a través de un enlace.

- Usar tags y metatags en la información que colocamos en la red para facilitar que sea encontrada cuando la buscan.

- Google Alerts es una herramienta excelente que nos permite estar notificados si alguien está hablando sobre nuestra compañía, nuestra competencia, sobre nosotros, o algún otro tema importante.

- Blogpulse nos revela los blogs y bloggers que tienen una autoridad en torno a temas de moda o tópicos de inusual relevancia social.

- Technorati permite descubrir blogs queé cubren determinadas palabras clave.

- Explorar su blogroll. Un blogroll es una colección de enlaces de blogs para encontrar más weblogs, normalmente presentado cuando aparece en un lateral de la página.

- Usar un agregador de contenidos, RSS o un lector de noticias para simplificar el proceso de leer los blogs importantes y su cobertura.

- Leer los comentarios y participar si se considera conveniente.

- Los comunicados de prensa, sólo tendrán sentido para anuncios muy importantes y verdaderamente masivos o cuando se debe cumplir con regulaciones financieras, por ejemplo, donde la información debe ser la misma para todo el mercado. Si bien creemos que cada vez se usarán menos, todavía tienen un lugar bajo el sol, ya sea en la forma de comunicados para medios tradicionales, comunicados optimizados para que puedan ser encontrados fácilmente por un buscador, comunicados para clientes, y comunicados en medios sociales o Social Media Releases (SMR) para la prensa, los bloggers y también los clientes, que veremos más adelante.

Aquellos profesionales que sepan incluir estas actitudes y herramientas en la planificación de su comunicación lograrán cumplir con las exigencias que plantean los nuevos medios y serán capaces de crear verdaderas relaciones con ellos.

De hecho, y según una encuesta efectuada por la agencia de relaciones públicas argentina Mazalán Comunicaciones-, el 67 por ciento de un grupo de 40 consultoras de Comunicación y Relaciones Públicas de 26 países de todo el mundo usa Twitter para enviar información a la prensa. Aunque todavía el e-mail es el medio preferido. Según puede observarse en las siguientes figuras.

¿Qué tipo de herramientas utilizas para compartir información de prensa con los medios de tu país?

$\begin{array}{lll}\text { e-mail text } & 35 & 85 \% \\ \text { e-mail html } & 23 & 56 \% \\ \text { website propio } & 13 & 32 \% \\ \text { blog propio } & 9 & 22 \%\end{array}$




$\begin{array}{lll}\text { teléfono } & 31 & 76 \% \\ \text { fax } & 7 & 17 \% \\ \text { Otro } & 14 & 34 \%\end{array}$

Puede haber más de una selección. Por ello el \% total es mayor al 100\%.

¿Están utilizando alguna herramienta de Social Media para compartir información de sus clientes?

$\begin{array}{lll}\text { Facebook } & 22 & 61 \% \\ \text { Linkedin } & 17 & 47 \% \\ \text { Hi } 5 & 1 & 3 \% \\ \text { Twitter } & 24 & 67 \% \\ \text { Youtube } & 22 & 61 \% \\ \text { Otro } & 6 & 17 \%\end{array}$

Los encuestados pudieron seleccionar más de una casilla, por lo que los porcentajes pueden ascender a más del 100\%.

¿Desarrollan campañas de publicidad online integradas con iniciativas de Relaciones Públicas? $\mathrm{Si}$

No $\quad 6 \quad 15 \%$

Por ahora no $\quad 17 \quad 43 \%$

Julian Tanner de Axicom, en Reino Unido comentó que "el uso de las nuevas herramientas dependen de las audiencias. Para clientes de tecnología se ve una gran utilización de Twitter. Personalmente creo en LinkedIn como una herramienta de uso masivo en el mundo de los negocios, pues permite un relacionamiento B2B sin SPAM."

Susanne Haeckel, de Schwartz PR, Alemania, indicó que "si, los medios sociales son un gran influenciador, el flujo de información, la velocidad y la dirección ha cambiado a través del uso de redes de medios de comunicación social, incluyendo la forma de obtener información. Esta ahora se maneja mucho más directa e inmediatamente".

Ricardo Cesar de Agenca Ideal de Brasil ve la gran oportunidad de "medir los resultados" con el uso de las redes sociales y asegura que con ellas puede segmentar muy bien sus audiencias y establecer "conversaciones" con ella.

Para Migle Mackeviciute, de Komunikacija ir konsultantai de Lithuania, "las redes son populares hoy, pero es difícil juzgar sobre la influencia en el futuro."

Amanda Hassall, de Six Degrees en Reino Unido, asegura que no sólo son apropiadas para relacionarse directamente con los usuarios, sino para hacerlo con referentes e influenciadores clave. "Es esencial que las empresas integren sus estrategias de comunicación online y offline", por su parte Jennifer Janson comentó que Twitter es muy poderoso (y utilizado por todos los periodistas importantes de Inglaterra), pero parece estar llegando a un punto de inflexión, por lo que están buscando la próxima novedad.

Stephan Fuetterer, de Best Relations, en España afirma que las campañas "deben ser administradas correctamente y pensando a largo plazo. La empresa debe estar comprometida con este tipo de iniciativas que no son sólo para dedicarles 30 minutos de trabajo al día a cargo de la gerencia de relaciones públicas"

Blogs, podcasts, twitteros, y sitios web en general han creado un ciclo de noticias que está abierto 
las 24 horas. Cuando antes existía una hora de cierre determinada, ahora las noticias están disponibles y son consumidas en un ciclo prácticamente sin fin. La agencia de noticias estadounidense United Press International publicó hace muchos años un libro de su propia historia llamado Cada minuto un cierre reflejando el ritmo con el que una agencia internacional de noticias trabajaba. Ese criterio se ha trasladado ahora y puesto a disposición para el gran público por internet.

Ya no existe la época en que una noticia podía pasar más o menos inadvertida, como el viernes a la tarde. Hoy se puede esperar que todo lo que salga en Internet, y todo saldrá en internet, tenga una audiencia numerosa e interesada.

Así que, mientras con los atareados periodistas se debería evitar el comunicado de prensa y trabajar en historias enfocadas a partir del interés de cada uno de ellos, deberíamos reservar esos mismos comunicados, pero pensados para una nueva era de buscadores e internet, que llegarán directamente a las audiencias, analistas y cualquier interesado en nuestra compañía u organización.

\section{Los desafíos a enfrentar}

Anteriormente hemos sostenido que los cambios provocados por la irrupción de la web social ha hecho que buena parte de las audiencias dejaran de ser receptoras pasivas de mensajes; que para las relaciones públicas ya no se trate de llegar con un mensaje, sino de escuchar y responder a la conversación, y que desde el punto de vista de las organizaciones y empresas ya no se trate solamente de ir donde se piensa que están las audiencias sino también estar cuando las audiencias son las que las buscan.

Sostuvimos que en esta matriz de muchas variables, o tablero de ajedrez en varios planos, el profesional de comunicaciones, ahora, debe agregar el mundo online a su estrategia. Esto implica sumar nuevos influenciadores como bloggeros y twitteros; y, en general, ver el proceso de comunicación en forma holística y no parcializada. Las audiencias están en varios lugares a la vez, al tiempo que reciben y producen información y contenido.

Sin entrar en predicciones apocalípticas, es cierto también, que la cantidad de lectores de diarios de papel sigue en baja y que los diarios online, los agregadores de noticias, RSS y otros mecanismos de la web han hecho que muchas audiencias hayan migrado al mundo online para obtener su dosis diaria de información. A mediados de 2009, y con más de una década de ediciones en internet, muchos de los principales diarios latinoamericanos seguían debatiendo si debían tener dos redacciones independientes -una online y otra para el papel-, se cuestionaban la viabilidad de las versiones online en un mundo donde la gente espera contenido gratis en internet, y se sentían amenazados por la contínua reducción de ingresos publicitarios y por ventas de las ediciones en papel.

La crisis comercial del periodismo tiene efectos en cómo los departamentos de comunicaciones deben desarrollar su trabajo. Muchas redacciones se han reducido, existe una alta rotación de periodistas, y no es raro el caso de periodistas 'multimedia' que escriben, graban audio, filman un video -y hasta sacan fotos- para una edición online, además de escribir para la edición del día siguiente en papel.

Este nuevo mundo es un desafío para las comunicaciones, porque si siempre fue necesario ofrecer información oportuna y noticiosa, ahora con periodistas sobrecargados de trabajo y con necesidades multiplataformas -papel, online, audio, video, fotos, textos- el éxito de la ges- 
tión también estará determinado, en muchos casos, por la forma en que podamos facilitar el trabajo a esos reporteros.

Para Silvina Moschini, una consultora regional de comunicaciones y CEO de Intuic, que emplea intensamente herramientas online de relacionamiento con medios, "existen dos formas de relacionarse con la prensa, una es proactiva y otra es reactiva. Reactiva sería reaccionando a los postings de los periodistas. Es decir, un periodista que busca opiniones y emplea por ejemplo Haro o Profnet. Y la otra, proactiva, donde yo quiero proponerle una historia de prensa a periodistas que están en Miami, tanto de radio ó de televisión, como de medios impresos enfocados al área de tecnología y pequeñas y medianas empresas. A partir de eso se hace una lista de periodistas a los que les vas a estar enviando un pitch armado con el ángulo interesante que puede tener tu cliente, más datos de la industria u otros y comenzás diciéndole "Hola como sabes, el desempleo cayó en un 5\% debido a la crisis. Te quería sugerir a tal persona de tal empresa para poder hablar de tal y cual cosa". Entonces, uno sugiere el tema, la historia y se le sugiere a tal persona para que entreviste y se le fundamentas por qué es una buena historia y por qué esa persona podría ser un referente".

Pero además, como vimos, la posibilidad de comunicarse directamente con las audiencias es una oportunidad que antes no se había presentado con tanta claridad y que permite, si bien no siempre, prescindir de los 'medios' o al menos complementarlos toda vez que sea posible. Muchas veces una historia recogida por un blogger influyente o muy comentada en Twitter termina siendo recogida por los medios convencionales o el video viral en YouTube salta a la pantalla del noticiero en horario central.

\section{Comunicados de prensa enfocados en la audiencia, usuarios y clientes}

Las empresas y profesionales de marketing pueden usar servicios de distribución para complementar los comunicados de prensa escritos por periodistas y bloggers, para alcanzar a los clientes directamente a través de motores de búsqueda tradicionales, así como servicios de agregación de noticias como Techmeme ${ }^{2}$.

En el transcurso de los últimos meses, BusinessWire y PRNewswire han clasificado dentro de las 100 mejores fuentes de noticias en la tabla de posiciones de Techmeme ${ }^{3}$. Y, de acuerdo con un reciente estudio de Outsell, más del 51\% de los profesionales IT informaron que obtienen sus noticias de comunicados de prensa en Yahoo! y Google News, superando a los periódicos o revistas comerciales u orientadas a industrias específicas.

No es sólo tecnología. Cuando se implementan con llamados y enlaces a la acción, y si se leen en una forma que persuada a las personas o clientes, encontraremos que usualmente son convencidos a actuar. El truco para esta nueva raza de comunicados de prensa es escribirlos como el artículo que queremos leer. Mantenerlo limpio, claro, pseudo imparcial, pero definitivamente enfocado a los beneficios para clientes específicos. Básicamente, humanizar la historia que queremos contar.

Cuando ampliamos nuestra noticia o historia en un comunicado de prensa, es también importante reconocer que la mayoría de los formatos tradicionales que se han venido usando ya han pasado de moda. Sin embargo, hay espacio en nuestra actividad para un comunicado bien escrito que transmita valor, beneficios y una historia que sea relevante para cada destinatario. De todas formas, es más fácil decirlo que hacerlo. La mayoría de los comunicados de prensa están 
impulsados por el departamento de desarrollo de producto, el cual genera una visión desde el interior de la empresa. La versión final por lo general termina llena de adjetivos, jerga técnica y publicidad o lenguaje de marketing que exagera las características buenas para supuestamente generar más atención, con muy poco valor real desde el punto de vista de la comunicación. La publicidad tiene un lenguaje que la comunicación corporativa nunca debe adoptar.

Los periodistas son escépticos y por lo general no comparten el entusiasmo de los publicistas, en muchos casos no escribirán sobre una empresa o producto sino sobre una tendencia, o de cómo un producto afecta la vida de las personas, por ello, los mejores comunicados serán aquellos que estén enfocados hacia fuera y que sean un reflejo del estado del mercado, de cómo encajamos en él, y de lo que hay en él para los potenciales clientes, de cómo el producto o servicio los ayuda a resolver un problema real.

En este contexto, es importante terminar con las frases hechas. Todos saben que estamos entusiasmados con lo que sea que estamos anunciando, y que somos líderes, cualquiera sea el significado de ser líder, pero eso no llamará en absoluto la atención de un periodista digno de ejercer la profesión. Si la frase no es genuinamente de la persona que la dice y tiene poco o ningún valor para las implicaciones de la noticia, entonces solo resta y será mejor dejarla afuera.

\section{Comunicados de prensa y SEO}

En un mundo donde la gente busca información sobre nuestras compañías es necesario tener en cuenta la integración de palabras clave, frases y enlaces en un comunicado que, a su vez, optimizan la posibilidad de ser encontrados y la posición dentro de los motores de búsqueda tradicionales como Google o Yahoo!

En este caso, obviamente, los mejores targets para comunicados SEO son realmente los clientes, no los periodistas.

Está claro que los clientes utilizan motores de búsqueda para encontrar soluciones y, frecuentemente, los comunicados de prensa les brindan la información que necesitan para tomar decisiones, si están sobriamente redactados, poseen links a sitios Web con información relevante, precios, condiciones u ofertas específicas.

Más allá de que una empresa puede usar programas como AdWords para incrementar el tráfico hacia sus sitios web, es cierto también que una buena optimización de sus comunicados ayudará que los buscadores coloquen a la información que queremos llegue a nuestras audiencias en las primeras páginas de sus resultados. Los comunicados optimizados para ser encontrados por buscadores contribuyen a establecer los resultados de búsqueda relacionados.

En la elaboración del comunicado, es imprescindible que las palabras clave estén incluidas en el frente del comunicado, especialmente en el título y subtítulo, así como también en el boilerplate. Una idea es tomar tres palabras clave y repetir las mismas a lo largo del comunicado. Los motores de búsqueda parecen prestar más atención a las palabras en negrita naturales así como a las palabras repetidas en la parte superior de la nota -en la primera mitad-. También es muy útil utilizar estas palabras clave como texto de enlace para vincular con landing pages estratégicas en los sitios web.

La densidad de palabras clave -el número de veces que una palabra clave o frase aparece en comparación con el número total de palabras en una página- es optimizado entre un $2 \%$ y un $8 \%$ según los expertos. Obviamente es importante incluir los nombres de la industria y de los 
productos y categorías en lugar de genéricos, como 'el producto', 'la solución', y 'la empresa' a lo largo de la nota, sin arruinar la fluidez. Se deben combinar nuestras palabras clave para tener un correlato con los patrones de búsqueda de la gente del mundo real.

Hay libros enteros dedicados al SEO que analizan estos y otros temas relacionados en profundidad, pero lo importante es incorporar el concepto que en un mundo donde la gente encuentra lo que busca debemos redactar comunicados con esa idea en la cabeza y dejar de lado, de una vez y para siempre, la forma tradicional de redacción que nos ha acompañado en el último siglo.

\section{Comunicados de medios sociales o SMR}

En los Estados Unidos se ha comenzado a hablar de comunicados para medios sociales o Social Media Release (SMR). Originalmente fueron presentados por Todd Defren ${ }^{4}$ en respuesta a la llamada de Tom Foremski ${ }^{5}$ para acabar con los comunicados de prensa, los SMR representan un nuevo formato socialmente arraigado que complementa los comunicados de prensa SEO y tradicionales a través de la combinación de nuevos hechos y activos sociales en una sola herramienta. En general, los comunicados de prensa no aprovechan las capacidades multimedia de internet -todavía hay muchos que los siguen enviando por fax-. La mayor parte de las veces son emitidos sin video o audio y muchos aún no incluyen enlaces a información adicional o contenido de apoyo. Aunque estas piezas son componentes subyacentes de los SMR, no se trata sólo de contenido multimedia, se trata de conectar información a través de redes sociales, de la gente que la busca, así como de las conversaciones que las unen. Y los SMR ayudan también a los bloggers y periodistas online a escribir historias usando un recurso que les proporciona todo lo que necesitan.

Un SMR cuenta con un título, párrafo introductorio, noticias, hechos, citas e información de apoyo a través de enlaces; y se combina con contenidos socializables insertados, como vídeos de Viddler ${ }^{6}$, fotos de Flickr, videos alojados en YouTube, documentos de apoyo, herramientas sociales para hacer bookmarks, etiquetas relevantes para la indexación por parte de los buscadores, suscripciones a través de RSS y contactos de la empresa a través de Facebook o LinkedIn. Como los comunicados de SEO, los SMR ofrecen además un nuevo y quizás imprevisto beneficio. De la misma manera en que los comunicados de SEO brindan asistencia a los clientes que buscan soluciones a través de la búsqueda, SMR ofrece beneficios similares a través de canales sociales. La diferencia está en cómo la gente interactúa con ellos, en cómo los descubren y en las herramientas que utilizan para compartirlo y reenviarlo. Básicamente, un SMR debe contener todo lo necesario para compartir, descubrir y recontar una historia en una forma que sea complementaria a su intención y contexto originales.

Deberían ser alojados en el blog de una empresa. Cualquier plataforma de blog que pueda personalizarse hará más que servir como una plataforma social y efectiva. Hay que tener en cuenta que una página web tradicional no es necesariamente social, por lo que probablemente cualquier SMR publicado en un sitio web estándar no aparecerá en las búsquedas sociales que hagan los miembros de Facebook, por ejemplo.

\section{La redacción online}

En el año 2001, el departamento de comunicaciones de la empresa Cisco Systems en América Latina llevó a cabo una encuesta entre periodistas de la región para preguntarles cómo querían 
recibir información. Ya por entonces, se vislumbraba que el comunicador tradicional y el papel iban camino a ser despreciados en las redacciones. Los resultados de ese estudio realizado por la firma Kaagan Associates de New York permitieron a Cisco poner en el aire una de las primeras redacciones online, donde los periodistas podían recoger información, fotos, videos, white papers, artículos técnicos y a su vez suscribirse para recibir sólo la información que les interesaba. Esta era enviada por e-mail en forma de newsletter semanal. Evitando el bombardeo de comunicados y dejando a los equipos de comunicación locales el tiempo suficiente para trabajar con los periodistas clave en historias específicas uno a uno.

Varios años después, en 2008, un estudio realizado por el grupo TEK y Bulldog Reporter en Estados Unidos puso en evidencia la necesidad imperiosa de contar con una redacción de noticias online para llevar a cabo una mejor relación con los medios. Entre los periodistas entrevistados, un $100 \%$ declaró que es importante que las compañías cuenten con una redacción de noticias online. Por otro lado, el 93\% declaró que visita estos sitios tanto en empresas grandes como en PyMes; y un 98\% manifestó su interés en recibir e-mails generados a través de estas redacciones de noticias.

En el capítulo siguiente nos referiremos en profundidad a este tema.

\section{Visibilidad en los buscadores de noticias}

El gran beneficio que tenemos en los buscadores de noticias es que la persona que consume la información está realmente interesada en el contenido, porque estaba búscandolo antes de encontrarlo. A diferencia de los medios offline, donde no sabemos cuál es el contexto en el que se presenta la noticia, ni la actitud o el estado mental que posee el público; aquí tenemos la seguridad de que el receptor tiene una muy buena disposición frente a la información que le estamos mostrando.

El alcance que tenemos a través de Google es de una gran magnitud, porque casi el 85\% de los usuarios latinoamericanos realiza sus búsquedas desde allí. Ahora el propósito de Google es que las búsquedas se realicen sobre todo el contenido disponible cualquiera sea su formato y decidió llamar a esta iniciativa Universal Search. Lo que queremos destacar con esto, es que las noticias ya no sólo podrán mostrarse en la sección de noticias, sino que pueden alcanzar a todos los usuarios que realizan su búsqueda a través de Google. Por lo tanto, con este cambio es más importante que nunca que desarrollemos tareas de optimización y que acompañemos las noticias con imágenes, archivos de videos y podcasts.

Por otro lado, los estudios sobre el recorrido que realiza la mirada frente a una página de búsqueda comprobaron que es más visible aquello que se presenta acompañado de una imagen, que lo que sólo contiene texto. Las imágenes nos ayudarán a ganar visibilidad y, además, otros medios podrán utilizarlas para difundir la noticia. Aquí es importante que etiquetemos correctamente cada una de ellas y, en caso de no contar con un sitio de noticias que nos permita hacerlo, lo mejor será que acudamos a los webmasters para que lleven a cabo esta tarea.

En agosto de 2007 Google anunció que abriría la posibilidad de ingresar comentarios en la sección de noticias. Esta función sería exclusiva para los participantes, que son aquellos individuos mencionados o relacionados a la noticia; e, incluso, los redactores de la historia son considerados participantes por Google. Por lo tanto, si nuestra compañía está vinculada con la noticia, podremos ampliar el contenido y realizar aclaraciones, mejorando la cobertura de la misma. 
Las instrucciones expresadas en el sitio de Google dicen lo siguiente: "Si usted fue mencionado en alguna historia y le gustaría incluir un comentario en Google News, sólo tiene que enviarnos un mail a news-comments@google.com el mail debe incluir: su comentario, un enlace hacia la noticia que desean comentar, información de contacto -nombre, cargo y organización- y una manera de verificar su dirección de mail".

No tenemos por qué conformarnos con generar visibilidad en los buscadores; además, debemos tratar de ganar presencia en otros sitios de noticias que posean credibilidad -sobre todo aquellos que sean indexados por Google News y Yahoo News- porque esto nos ayudará a construir una visibilidad y credibilidad. En la web hay muchos espacios de noticias que están voraces por recibir contenido contundente. Lo mejor que podemos hacer, entonces, es ingresar nuestras palabras clave en un buscador y observar cuáles son los sitios que contienen contenido relacionado con nuestra industria. Tras estudiar correctamente el contenido del sitio, lo que deberemos hacer es escribirle un artículo a los responsables de su contenido y tratar de vender nuestra noticia. Tener nuestro contenido en estos lugares nos ayudará a llegar a nuestro público objetivo y a nuevos buscadores de noticias.

\section{La implementación de los RSS}

En este último tiempo, los RSS se han popularizado a gran velocidad. La razón es clara: los periodistas -e individuos- encuentran muy útil a esta herramienta, porque los ayuda a organizar y controlar la gran cantidad de información que circula en la web. Poner el contenido de nuestras noticias en un RSS lo pondrá a disposición de otros usuarios y sitios webs. Si todavía no hemos instalado un agregador de noticias y no sabemos cómo hacerlo, existen servicios como el de PRESSfeed ${ }^{7}$ que pueden hacer todo el trabajo pesado por nosotros. Una vez instalado, podremos sindicalizar nuestras noticias en pocos minutos y subir el contenido a nuestro sitio web sin la necesidad de aprender a realizar tareas de programación.

Una de las cosas que el RSS puede hacer por nosotros, es incrementar el tráfico del sitio. Los buscadores le están prestando mucha atención a la sindicalización de contenido. Una de las formas de hacer que nuestro contenido sea indexado por Yahoo! es agregar el material en $M y$ Yahoo! Además, agregadores de noticias como Google Readers, Bloglines ${ }^{8}$ o Netvives ${ }^{9}$ o reúnen el contenido proveniente de los RSS y poseen una audiencia en crecimiento que acude a ellos en busca de nuevo material.

También deberemos educar a nuestros lectores a mantenerse actualizados y para elle debemos comunicarle a las visitas del nuestro sitio que poseemos el servicio de RSS. Esto implica, no sólo incluir el ícono de color naranja que dice 'RSS', sino que también tenemos que incluir enlaces vistosos hacia la página de inicio en todas las páginas para que las visitas comprendan que ofrecemos el servicio de sindicación de contenido.

\section{En síntesis}

Tradicionalmente ha habido una desconexión entre las agencias de relaciones públicas, los departamentos de comunicaciones corporativas y los periodistas. La web 2.0 puede ayudarnos a reducir esta distancia si usamos las herramientas adecuadas para llegar a los públicos (y los medios son un público también) adecuados en el momento adecuado. 
Frente al bombardeo de comunicados de prensa que invaden las casillas de mails de los periodistas, tanto online y offline, y a la dificultad creciente que tenemos quienes hacemos relaciones públicas de ser escuchados en medio de esa cacofonía, hemos puesto a disposición del lector un nuevo modo de pensar la relación con los medios.

Las herramientas, sin embargo no reemplazan el contacto directo, la relación personal y el conocimiento profundo de las exigencias, los límites y las urgencias del periodismo moderno sino que en todo caso la potencian y extienden. Nunca creímos que las relaciones públicas se puedan llevar a cabo en forma efectiva sin salir a la calle.

El desafío, entonces, reside en alcanzar dos objetivos principales: la personalización y la riqueza informativa. Esto hoy es posible gracias a la información que podemos obtener antes de realizar el pitching con un periodista, por un lado, y por la diversidad de formatos y recursos con los que podemos producir el contenido que buscamos difundir, por el otro.

Los influenciadores del mundo online se encuentran dispersos en diversas plataformas, por lo que debemos elaborar estrategias comunicativas que alcancen a todas ellas, de manera holística. Los comunicados SEO, SMR y la creación de una redacción online nos ayudaran a hacerlo. Asimismo, una de las condiciones que se imponen en la comunicación corporativa para poder generar influencias es iniciar un proceso de apertura y un esfuerzo por acercarnos al nivel de la audiencia $\mathrm{o}$, en otras palabras, a una horizontalidad en la relación con ellos.

Este es un llamamiento a introducirnos en el diálogo abierto y relacional que proponen los nuevos medios y que tiene sus propias reglas del juego. Una vez adentro, veremos con nuestros propios ojos lo que somos capaces de hacer en el mundo de los peers.

\section{Notas}

1 http://www.uberbin.net/

2 www.techmeme.com

3 www.techmeme.com/lb

4 Acá Tom Defren hablá sobre las plantillas de SMR

www.pr-squared.com/2008/04/social_media_release_template.html

5 El artículo de Tom Foremski Die! Press release! Die! Die! Die! www.siliconvalleywatcher.com/ mt/archives/2006/02/die_press_relea.php

6 www.viddler.com

7 www.press-feed.com

8 www.bloglines.com

9 www.netvibes.com

\section{Referencias Bibliográficas}

Arébalos A. y Alonso G. (2009). La Revolución Horizontal. Buenos Aires: Ediciones B. 
Summary: This article corresponds to chapter XI of the book The horizontal revolution - the power of the communication into people hands, presented by the end of 2009 in the Faculty of Design and Communication of the University of Palermo. Its authors - Alberto Arébalos and Gonzalo Alonso-reflect on keys to understand changes in the form in which the brands, companies and politicians are related and communicated with the consumers, clients and voters. This chapter, approaches the challenge of public relations and media relations management, using a series of tools that empower and renew traditional tools, from a new emergent relational culture. It reflects on the optimization of press releases, on systems like RSS that multiply the reach of corporate news; and on the expensive news releases videos that now with a smaller cost, can reach bigger audiences.

Key Words: audience - brand - Communications people - Communications Director Corporate reputation - Corporate Communications - Digital Communication - Dircom - External public - Institutional Communication - Institucional Relations - Internal public - Media Relations - Press Relations - Public Relations - relationships - social media - Social networks - trends.

Resumo: Este artigo corresponde ao capítulo XI do livro "A revolução horizontal - O poder da comunicação em maos das pessoas", apresentado ao fins de 2009 na Facultade de Design e Comunicação da Universidade de Palermo. Os autores, Alberto Arébalos y Gonzalo Alonso-, reflexionam sobre as claves para entender a mudança na forma em que as marcas, empresas e políticos relacionam-se e comunicam com os consumidores, clientes e votantes. Pontualmente este capítulo, aborda o desafio da gestão das relações públicas e as relações com os meios, empregando uma série de ferramentas que potencian e renovam ferramentas tradicionais, a partir duma nova cultura relacional emergente. Reflexiona sobre a otimização dos comunicados de imprensa, sobre mecanismos como RSS que multiplicam o alcance das notícias corporativas; e sobre os custosos videos news releases que agora com um menor custo, podem atingir audiências maiores.

Palavras chave: audiências - Comunicação Corporativa - comunicação digital - Comunicação Institucional - comunicação organizacional - Comunicadores - Dircom - Diretor de Comunicação - marcas - público externo - público interno - redes sociais - relações - Relações com a prensa - Relações com os meios - Relações Institucionais - Relações Públicas - reputação corporativa social media - tendências.

(*) Director de Comunicaciones Corporativas y Asuntos Públicos de Google, a cargo de la región de Latam con base en Buenos Aires. [Ver CV completo en la página 152] 